\title{
New IBD markers: Definition of disease heterogeneity
}

\author{
STEPHAN R TARGAN MD
}

\begin{abstract}
SR TARGAN. New IBD markers: Definition of disease heterogeneity. Can J Gastroenterol 1995;9(6):301-304. There is emerging evidence that serum and mucosal markers differentiate Crohn's disease from ulcerative colitis; moreover, subgroups can be defined within each disease. Subgroups have been defined on the basis of genetic, serum and mucosal markers, and are associated with different clinical phenotypes. Antineutrophil cytoplasmic antibodies (ANCA) define subgroups of patients with both ulcerative colitis and Crohn's disease. A new serum marker, 20P-1, has been found in 60 to $70 \%$ of patients with Crohn's disease, $20 \%$ of ulcerative colitis patients and approximately $10 \%$ of the normal control population. The 20P-1 marker further stratifies the subgroups of patients defined by ANCA. In addition to serum markers, genes regulating production of the cytokine tumour necrosis factor (TNF)-alpha have been shown to be different across ulcerative colitis and Crohn's disease, and within the ulcerative colitis group. Serum markers may reflect differential mucosal inflammatory responses as is best shown by ANCA. B cell clones within the mucosa of 60 to $70 \%$ of patients with ulcerative colitis produce ANCA spontaneously. Studies currently underway demonstrate different TNF- $\alpha$ production within the mucosa of patients with Crohn's disease compared with ulcerative colitis patients. Correlation studies with TNF- $\alpha$ microsatellites (genes) are being performed. These markers are the focus of a trial using molecularly engineered products that are capable of inhibiting TNF- $\alpha$ to identify patients likely to respond to anti-TNF therapy. In this constantly evolving climate of understanding and treating inflammatory bowel disease, serum, mucosal and genetic markers as well as genetic associations are being formed to determine clinical phenotypes that may be differentially responsive to very selected treatment modalities. These advances highlight the likelihood that the various markers define differ-
\end{abstract}

continued on next page USA

Cedars Sinai Medical Centre, Inflammatory Bowel Disease Centre, Los Angeles, California,

Correspondence: Dr Stephan R Targan, Cedars Sinai Medical Centre, Davis Building, Inflammatory Bowel Disease Centre, 8700 Beverly Boulevard, Suite D4063, Los Angeles, CA 90048, USA. Telephone 310-855-7723, fax 310-652-7168

This paper was presented at the Trends in Inflammatory Bowel Disease Therapy meeting, April 6 to 9, 1994, held in Victoria, British Columbia. This paper has also been published in Sutherland LR, et al, eds. Inflammatory Bowel Disease: Basic Research, Clinical Implications and Trends in Therapy. Boston, Dordrecht and London: Kluwer Academic Publishers, 1994
$\mathrm{T}$ HE OBJECTIVE OF THIS PAPER IS TO relate recent findings that support the use of molecular and cellular techniques to define subsets of patients with inflammatory bowel disease (IBD). An example of the potential of using these methods to define disease subgroups by generic and subclinical markers involves an 'aggressive' form of rheumatoid arthritis that recently has been shown to express a specific human leukocyte antigen (HLA)-DR4 allele (1). This subgroup of patients with rheumatoid arthritis is defined clinically by a progressively active course that is resistant to standard therapy, including corticosteroids. These patients do, however, respond very well to treatment with the immune suppressant methotrexate. Patients with the HLADR4 allele now are placed immediately on methotrexate. Thus, this description of a subgroup of patients has led to a completely altered treatment proto$\mathrm{col}$, and is the first instance where a genetic marker has been used to define a subset of patients for treatment with a selected therapy in an immunologically mediated disease. In ulcerative colitis and Crohn's disease, subsets of patients also may be defined by genetic and subclinical markers that reflect specific types of mucosal inflammation, and each type may represent a unique opportunity for individualized treatment approaches. 
ent types of mucosal inflammation. The different types of mucosal inflammation will determine the response or resistance to certain types of therapeutic options.

Key Words: Crohn's disease, Intercellular adhesion molecule-1, Perinuclear antineutrophil cytoplasmic antibodies, Tumour necrosis factor-alpha, Ulcerative colitis

\section{Nouveaux marqueurs des MII : définition de l'hétérogénéité de la maladie}

RÉSUMÉ : Les preuves se multiplient à l'effet que des marqueurs du sérum et de la muqueuse différencient la maladie de Crohn de la colite ulcéreuse. De plus, des sous-groupes peuvent être définis à l'intérieur de chaque maladie. Ces sousgroupes ont été définis sur la base de marqueurs génétiques, sériques et muqueux et sont associés à différents phénotypes cliniques. Les anticorps antineutrophiles cytoplasmiques (ANCA) définissent les sous-groupes de patients atteints de colite ulcéreuse et de maladie de Crohn. Un nouveau marqueur sérique, le 20P-1, a été découvert chez 60 à $70 \%$ des patients atteints de la maladie de Crohn, chez $20 \%$ des patients atteints de colite ulcéreuse et chez environ $10 \%$ de la population témoin normale. Le marqueur 20P-1 stratifie davantage les sous-groupes de patients définis par ANCA. En plus des marqueurs sériques, les gènes qui régissent la production du facteur de nécrose tumorale cytokine (TNF)-alpha se sont révélés différents entre la colite ulcéreuse et la maladie de Crohn et à l'intérieur du groupe colite ulcéreuse. Les marqueurs sériques peuvent refléter les réponses inflammatoires différentielles de la muqueuse, comme le démontre bien l'ANCA. Les clones des cellules B à l'intérieur de la muqueuse de 60 à $70 \%$ des patients atteints de colite ulcéreuse produisent spontanément des ANCA. Les études actuellement en cours démontrent la production de différents TNF- $\alpha$ à l'intérieur de la muqueuse affectée par la maladie de Crohn en comparaison avec les patients atteints de colite ulcéreuse. Des études sont actuellement en cours sur les microsatellites du TNF- $\alpha$ (gènes). Ces marqueurs sont le point central d'un essai à base de produits fabriqués par génie moléculaire qui peuvent inhiber le TNF- $\alpha$ afin d'identifier les patients susceptibles de répondre à un traitement anti-TNF. Dans ce contexte où l'on cherche sans cesse à faire évoluer la compréhension et le traitement des maladies inflammatoires de l'intestin, les marqueurs sériques, muqueux et génétiques, de même que les associations génétiques sont examinés afin de déterminer les phénotypes cliniques qui peuvent répondre de façon différentielle à des modalités thérapeutiques très précises. Ces progrès rappellent que divers marqueurs peuvent définir différents types d'inflammation de la muqueuse. Les différents types d'inflammation de la muqueuse détermineront la réponse ou la résistance à tel ou tel traitement.

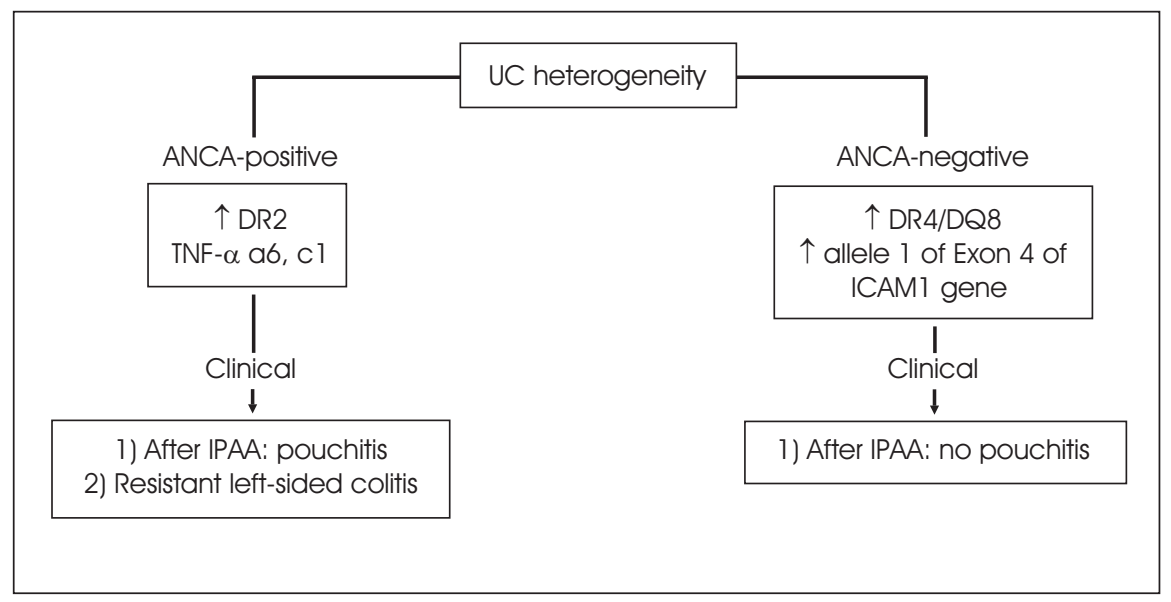

Figure 1) Ulcerative colitis as an example of a genetically heterogeneous syndrome. ANCA Antineutrophil cytoplasmic antibodies; ICAM Intercellular adhesion molecule; IPAA Ileal pouch anal anastomosis; UC Ulcerative colitis

\section{GENETIC AND SUBCLINICAL CHARACTERIZATION OF IBD PATIENTS}

HLA and antineutrophil cytoplasmic antibodies: As with other immunological diseases, subgroups of patients with IBD have a varied clinical presentation, and this has led to investigations to determine whether this variation represents a set of diseases that displays a similar clinical picture. The differences may be based on heterogeneous genetic backgrounds. Genetic heterogeneity was first shown in two diseases: type I diabetes and type II diabetes have different genetic profiles; and juvenile rheumatoid arthritis of a particular clinical phenotype has HLA associations different from the other types (3).

In recent years, a series of observations has suggested that within each type of IBD (particularly within ulcerative colitis but also currently emerging in Crohn's disease) there are heterogeneous clinical phenotypes. The following is a discussion of ulcerative colitis as an example of a genetically heterogeneous syndrome. These concepts are schematized in Figure 1.

Genetic and subclinical markers have been associated with ulcerative colitis. Particularly informative has been the finding that there is an increased association with HLA-DR2 and a decreased association with HLA-DR4 in ulcerative colitis. Furthermore, the population can be divided into patients who express antineutrophil cytoplasmic antibodies (ANCA) and those who do not. HLA associations differ based on the presence or absence of ANCA (4). HLA-DR2 is associated only with patients expressing ANCA while HLA-DR4 is associated with ulcerative colitis patients not expressing ANCA. Presence or absence of ANCA appears to breed true in families, ie, unaffected family members of ulcerative colitis probands with ANCA also have ANCA; the converse is also true (5). These initial findings suggest a correlation between ANCA and the so-called 'familial ulcerative colitis' which may differ from the 'spontaneous' ulcerative colitis that appears to arise in the absence of a family association.

A genetic or subclinical characteri- 
zation has been made recently, separating patients with familial colon cancer from those with spontaneous colon cancer. The initial gene associations were made with pedigrees of familial cancer. Subsequent studies will define the relationships of these gene alterations when spontaneous cancers arise in the general population.

ICAM1 and Exon 4: Initial data suggested that the serum marker ANCA may differentiate patients with two distinct types of colitis. Subsequent studies demonstrated additional genetic associations further describing the populations with and without ANCA. The intercellular adhesion molecule (ICAM) 1 is a critical structure located on many cell types and is very important for regulating the immune response. The gene structure for that particular molecule is now known and polymorphisms within that gene have been described (6). It is apparent that a different allele of the ICAM1 molecule in a particular part of the gene termed 'Exon 4' is differentially associated within the ulcerative colitis population. There is an increased association of Exon 4 with ulcerative colitis patients who do not express ANCA, but this increase is not noted in those who do. Thus, a second genetic association becomes apparent upon dividing the ulcerative colitis population by ANCA. These genes are associated with the regulation of inflammation, and the findings suggest that there may be a different type of mucosal inflammatory process among patients who have ANCA circulating in their serum compared with those who do not (7).

\section{SUBGROUPS DEFINED AT THE MUCOSAL LEVEL}

The presence of ANCA antibodies in the serum of ulcerative colitis patients potentially is a marker of an underlying selective immune regulatory abnormality manifested by a specific type of inflammation that may differ from inflammation in patients without this marker. This hypothesis was generated from the findings of several recent studies that have shown different familial, genetic and clinical associations between ulcerative colitis patients ex- pressing ANCA and those who do not (4-6). These findings support the thesis that ANCA is a marker that defines the mucosal inflammatory process of $\mathrm{ul}$ cerative colitis patients as different from the inflammation in patients who do not produce ANCA. If ANCA is a marker for a disease-related immune response process, it is assumed that there are $\mathrm{B}$ cells within the colonic mucosa that produce these antibodies. Studies have shown that ANCA-secreting B cell clones are present in only 60 to $70 \%$ of both involved and uninvolved mucosa of ulcerative colitis patients. This percentage parallels that found for the presence of ANCA in the serum of ulcerative colitis patients, suggesting that the presence or absence of serum ANCA reflects the mucosal B cell ANCA production. More important, this finding implicates these clones in a diseasespecific mucosal immune response in ANCA-expressing ulcerative colitis patients that differs from the mucosal response of ulcerative colitis patients not expressing ANCA. It is likely that the B cell clones that produce ANCA are involved in an ulcerative colitis-related immune response rather than ANCA antibodies playing a direct role in the disease pathogenesis. Therefore, the presence or absence of ANCA-producing $B$ cells may reflect a different mucosal inflammatory response occurring among the different groups of patients, and suggests that there could be distinct types of clinical disease that can be differentiated based on ANCA.

\section{SUBGROUPS DEFINED BY CLINICAL PARAMETERS}

An example of a subgroup defined initially by clinical parameters comprises patients with very severe disease who underwent an ileal pouch anal anastomosis and subsequently developed inflammation in those pouches. Investigations determined their genetic and subclinical marker profiles and distinctions were found. Most patients in this group expressed ANCA. By contrast, patients who had a similar operation but did not develop pouchitis did not express ANCA $(8,9)$. This study was the first investigation following a clinical observation. The investigation yielded corroborative and provocative results that further emphasized the heterogeneity among the population of patients diagnosed with 'ulcerative colitis'.

To date, the diagnosis of ulcerative colitis and the description of subpopulations have been made purely on an anatomical basis, ie, proctitis, left-sided colitis and pancolitis, or relative to their clinical presentation of mild, moderate or severe. However, the population has not been divided by 'type of inflammation', which may now be possible by separation along the lines of the markers defined above. Type of inflammation may be characterized by patient responsiveness to a particular medication as part of the natural history of the disease process. As has been shown in the example of rheumatoid arthritis, these markers may determine how 'aggressive' the process is and how 'responsive' it is to standard or 'progressive' courses of medication. It is now incumbent upon clinical researchers and physicians to characterize and stratify ulcerative colitis and Crohn's disease on the basis of the aggressiveness of inflammation and the extent of disease by molecular and cellular technology, in conjunction with the natural clinical course, and response to therapy.

An attempt was made to use the markers currently available to define an additional clinical group differentiated by ANCA. In conjunction with the Mayo Clinic we investigated the incidence of ANCA in left-sided colitis patients whose disease was resistant to the standard treatments including oral and intravenous corticosteroids. Ninety per cent of patients with 'resistant' leftsided disease had ANCA, substantially more than in the overall group of ulcerative colitis patients, of whom $60 \%$ express ANCA (10).

A similar pictures is now emerging in Crohn's disease. Although ANCA is present at low levels in only a small group of Crohn's patients (15 to 20\%), ANCA marks a gene association different from that in ANCA-free Crohn's disease patients (6).

In summary, building on our early findings, dividing subgroups of patients with IBD, and ulcerative colitis in par- 
ticular, we now have three 'levels' of differentiation: genetic and subclinical markers; mucosal cell profile; and clinical distinctions. It is likely that further markers will be found from this same base, and these concepts are being applied to other disease processes contemporaneously.

\section{PRESENT AND FUTURE OF TREATMENT BASED ON DISEASE HETEROGENEITY DEFINITION}

It is very important that when new trials of medications are initiated and when retrospective analyses of patient

\section{REFERENCES}

1. Weyand CM, Hikok K, Conn DL, Goronzy JJ. The influence of HLA-DRB1 genes on disease severity in rheumatoid arthritis. Ann Intern Med 1992;117:801-6.

2. Pociot F, Briant L, Jongeneel CV, et al. Association of tumor necrosis factor (TNF) and class II major histocompatibility complex alleles with the secretion of TNF- $\alpha$ and TNF- $\beta$ by human mononuclear cells: a possible link to insulindependent diabetes. Eur J Immunol 1993;23:224-31.

3. Nepom B, Nepom G, Schaller J, et al. Characterization of specific HLA DR4-associated histocompatibility markers in patients with juvenile rheumatoid arthritis. J Clin Invest 1984;74:287-91.

4. Yang H-Y, Rotter JI, Toyoda H, et al. Ulcerative colitis: A genetically populations are undertaken, markers are properly associated with the correct subgroups. An excellent example of such redefined patient populations in 1994 includes patients with ulcerative colitis and Crohn's disease who are resistant to corticosteroids, thus requiring immunosuppressive agents such as 6-mercaptopurine and methotrexate, or cyclosporine. Further definition could be obtained by determining response and nonresponse to various immunosuppressive agents. As in rheumatoid arthritis, these groupings would then 'mark' these patients so that they

heterogeneous disorder defined by genetic (HLA class II) and subclinical (anti-neutrophil cytoplasmic antibodies [ANCA]) markers. J Clin Invest 1993;92:1080-4.

5. Shanahan F, Duerr R, Landers C, et al. Neutrophil autoantibodies in ulcerative colitis. A family study with evidence for genetic heterogeneity. Gastroenterology 1992;103:456-61.

6. Yang H-Y, Vora DK, Targan SR, Toyoda H, Beaudet AL, Rotter JI. Intercellular adhesion molecule 1 gene associations with immunologic subsets of inflammatory bowel disease. Gastroenterology 1995;109:440-8.

7. Targan SR, Landers C, Vidrich A, MacDermott RP. Perinuclear antineutrophil cytoplasmic antibodies (p-ANCA) are spontaneously produced by B-cells from involved and may be treated with the appropriate modality at disease presentation.

Subgrouping of patients by genetic and molecular markers is the wave of the future, and our thinking about these diseases should be altered and patient populations stratified by these more modern concepts. By using the criteria described above, varying the mucosal inflammatory processes associated with a specific treatment response profile can accelerate the amount of time taken to find the best therapeutic options for the well defined patient.

uninvolved mucosa of ulcerative colitis (UC) patients. J Immunol. (Abst) (In press)

8. Sandborn WJ, Tremaine WJ, Batts K, Pemberton JH, Phillips SF. Definition of pouchitis following ileal pouch anal anastomosis (IPAA): a pouchitis disease activity index. Am J Gastroenterol 1995;90:740-7.

9. Vecchi M, Gionchetti P, Bianchi $\mathrm{MB}$, et al. p-ANCA reactivity in ulcerative colitis patients with and without pouchitis after proctocolectomy. Gastroenterology 1993;104:A796.

10. Sandborn WJ, Landers CJ, Steiner BL, Tremaine WJ, Targan SR. The prevalence of antineutrophil cytoplasmic antibody (ANCA) is unexpectedly high in patients with treatment-resistant, left-sided ulcerative colitis (UC). Gastroenterology. (Abst) (In press) 


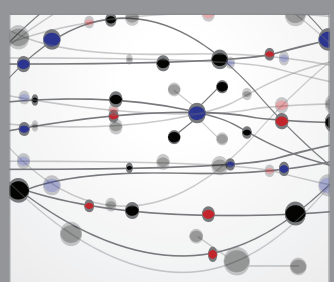

The Scientific World Journal
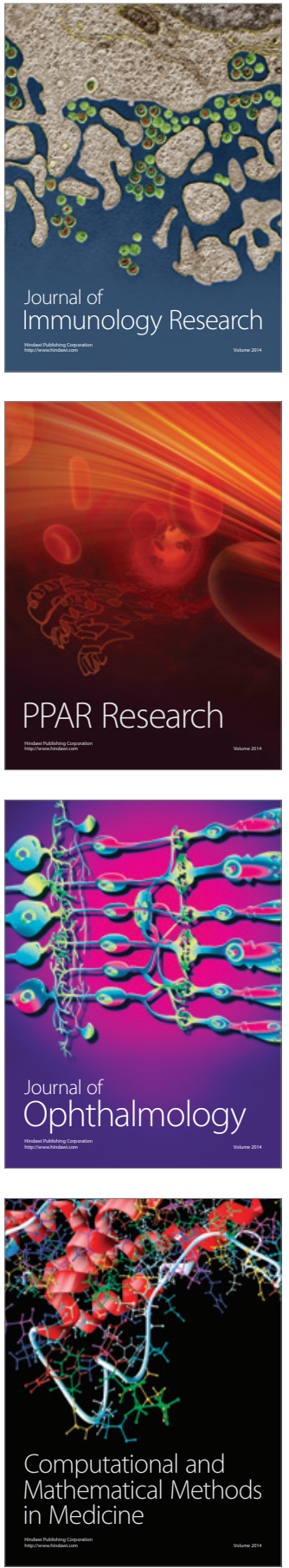

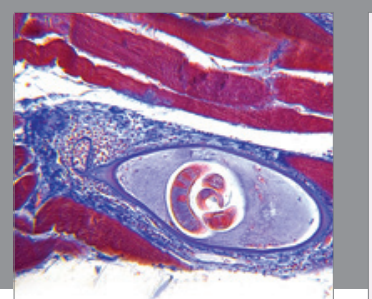

Gastroenterology Research and Practice

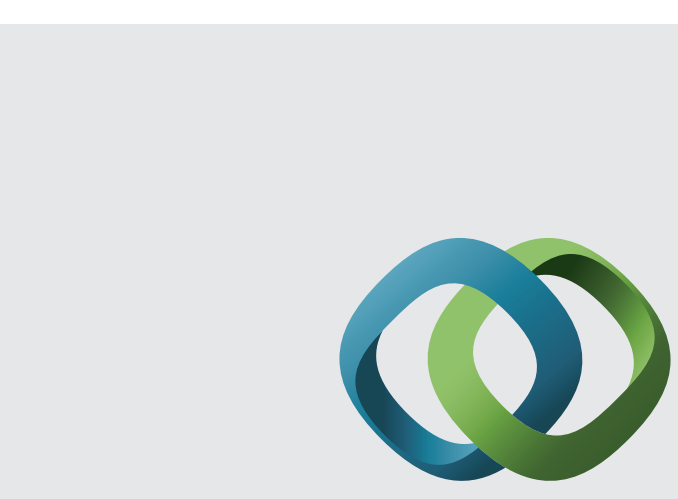

\section{Hindawi}

Submit your manuscripts at

http://www.hindawi.com
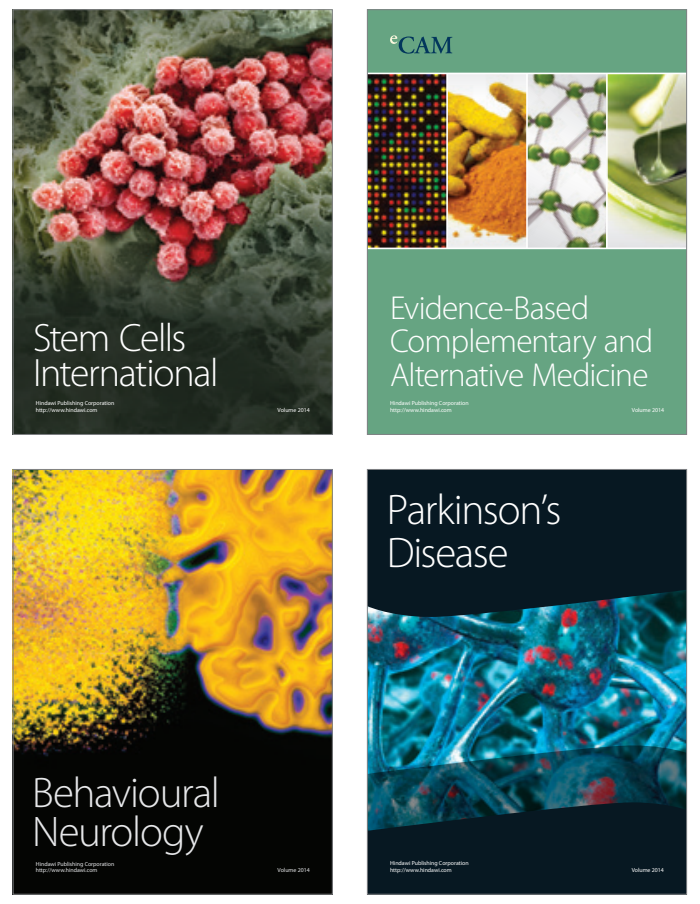
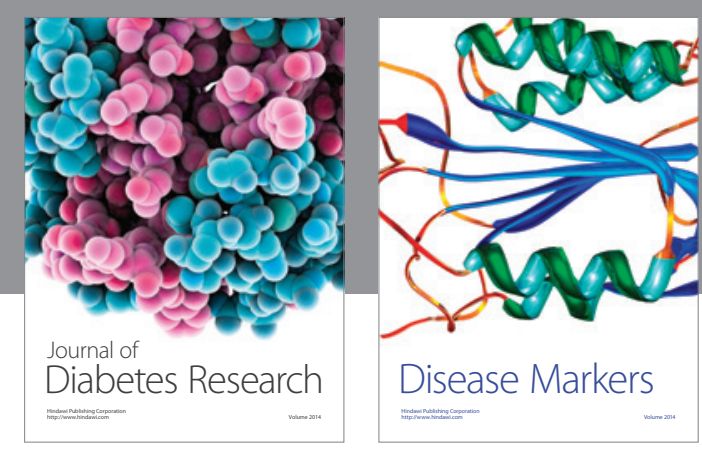

Disease Markers
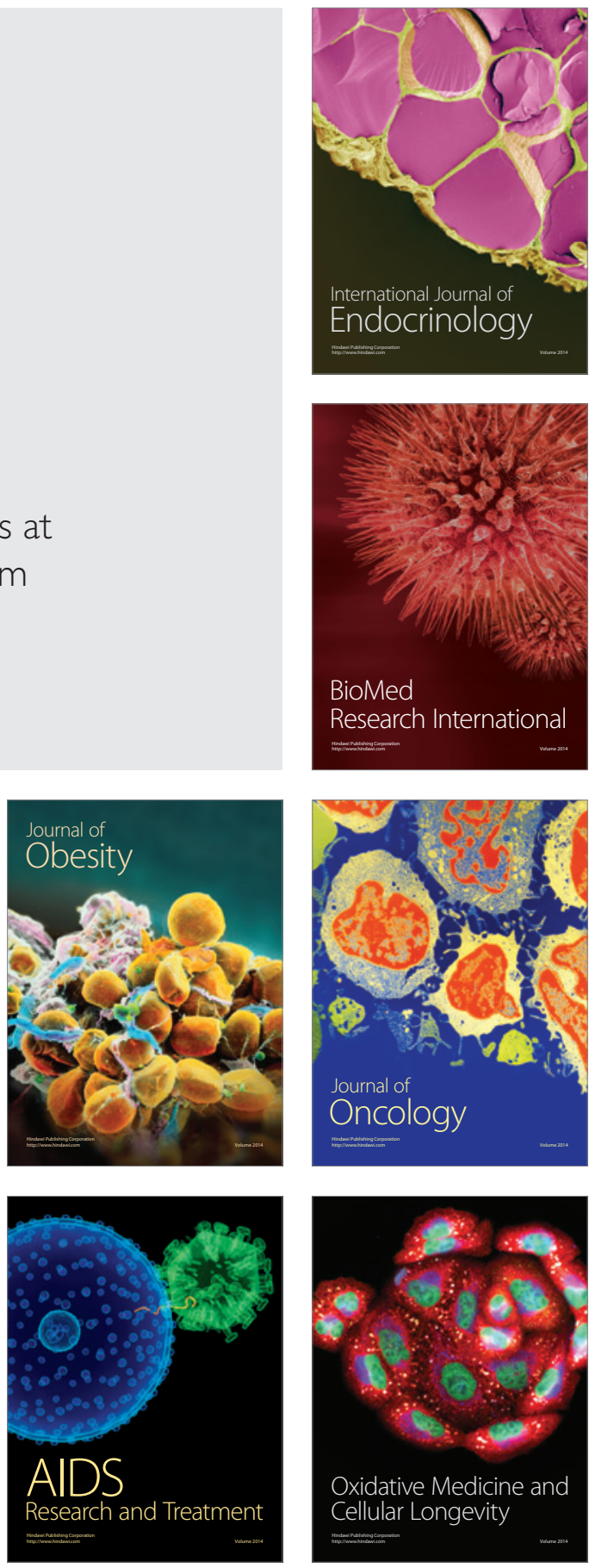